\title{
Overdiagnosis of Juvenile Thyroid Cancer
}

\author{
Toru Takano ${ }^{\mathrm{a}-\mathrm{c}}$ \\ ${ }^{a}$ Rinku General Medical Center, Izumisano, Japan; ${ }^{b}$ Department of Metabolic Medicine, Osaka University Graduate \\ School of Medicine, Suita, Japan; ' Department of Laboratory Medicine, Osaka University Graduate School of \\ Medicine, Suita, Japan
}

\section{Keywords}

Ultrasonography · Self-limiting cancer · Lethal cancer ·

Overdiagnosis - Thyroid

\begin{abstract}
Overdiagnosis is the detection of a disease that does not do any harm to the patient throughout the lifetime. Thyroid cancer in children is a rare disease; however, since 2011, many children in Fukushima, Japan, have been diagnosed with it, and the number has shown a steady increase to over 200 cases at present. Some experts have stated that this phenomenon is due to overdiagnosis caused by thyroid ultrasound (US)-based thyroid screening detecting self-limiting thyroid cancer, which will not lead to clinical symptoms in the future. Harm caused by overdiagnosis of thyroid cancer is more serious in the young, since it is difficult to perform active surveillance and children diagnosed with cancer are likely to suffer from stigma. Thus, overdiagnosis of thyroid cancer in the young is not only a health problem but also a problem of human rights. Conflicts of interest among people related to screening programs and some experts with incomplete knowledge on overdiagnosis help to spread misleading opinions together with fear of radiation exposure among residents, which has led to their erroneous understanding of the nature of US-based thyroid screening. Scien-
\end{abstract}

karger@karger.com www.karger.com/etj

Karger"
(C) 2019 European Thyroid Association Karger Published by S. Karger AG, Basel Open access This article is licensed under the Creative Commons AttributionNonCommercial-NoDerivatives 4.0 International License (CC BYNC-ND) (http://www.karger.com/Services/OpenAccessLicense) Usage and distribution for commercial purposes as well as any distribution of modified material requires written permission. tific and honest discussions among experts to enhance education of residents and consideration of medical ethics are crucial to prevent the expansion of overdiagnosis.

(C) 2019 European Thyroid Association Published by S. Karger AG, Basel

\section{Introduction}

Thyroid cancer in children is a rare disease found in only a few children in a million. Since the Great East Japan Earthquake and following the Fukushima Daiichi Nuclear Plant accident in 2011, many children in Fukushima, Japan, have been diagnosed with thyroid cancer, and the number has shown a steady increase to over 200 cases at present $[1,2]$. The epidemic is observed not only in Fukushima Prefecture but also in some cities near Fukushima, such as Marumori in Miyagi Prefecture and Kitaibaraki in Ibaraki Prefecture $[3,4]$. A common feature of these areas is that thyroid screening for children with ultrasonography (US) has been carried out by the local government. Some experts stated that the increasing incidence of juvenile thyroid cancer is not due to a true increase of patients, but is similar to what happened in Korea, due to overdiagnosis caused by US-based thyroid screening $[5,6]$. 
Clinical course of thyroid cancer in children and adolescents is different from that of thyroid cancer clinically found after middle age. In this review, thyroid cancer in the young is designated as juvenile thyroid cancer. This review summarizes the present status of children in $\mathrm{Fu}$ kushima and overviews the characteristics of overdiagnosis of juvenile thyroid cancer.

\section{Natural History of Juvenile Thyroid Cancer}

Thyroid cancer has long been considered to be generated by multistep carcinogenesis, in which cancer cells are derived from thyroid follicular cells, via multiple incidences of damage to their genome, and based on data on the prevalence of clinically evident thyroid cancer, the first event of carcinogenesis was believed to occur in middle age [7]. The Fukushima Health Management Survey (FHMS) showed data contradicting the above assumption. Just after the accident at the Fukushima Daiichi Nuclear Plant, a thyroid screening program involving US targeting about 380,000 children was started in Fukushima Prefecture [8]. Surprisingly, its data showed a high prevalence of thyroid cancer of over 30/100,000. Nearly all were papillary carcinoma and were regarded as unrelated to radiation [9]. These data proved that papillary carcinoma is a common phenomenon in children.

It is difficult to explain these results by the classical model of multistep carcinogenesis. Recently, 2 theories were proposed to explain thyroid carcinogenesis. One is early-onset multistep carcinogenesis, which was proposed by Williams (Fig. 1a) [10]. Thyroid cancers are generated from thyroid follicular cells in children. They keep growing in the young; however, the majority of them do not present as clinical cancer and remain small for the entire lifetime. Thus, after middle age, they are observed as papillary thyroid microcarcinomas (PTMs). A small number of them resume proliferation after some decades, and they turn into lethal cancers, which are observed after the forties.

The other is our fetal cell carcinogenesis model [11] (Fig. 1b). In fetal cell carcinogenesis, juvenile thyroid cancers arise from immature fetal thyroid cells and start proliferating before adolescence. They grow fast in the young but stop proliferating after middle age due to their selflimiting growth ability. Thus, juvenile thyroid cancers are regarded as self-limiting cancers. In fetal cell carcinogenesis, PTMs never turn into lethal cancers. Lethal cancers have completely different origins from those of juvenile cancers.

Overdiagnosis of Juvenile Thyroid Cancer

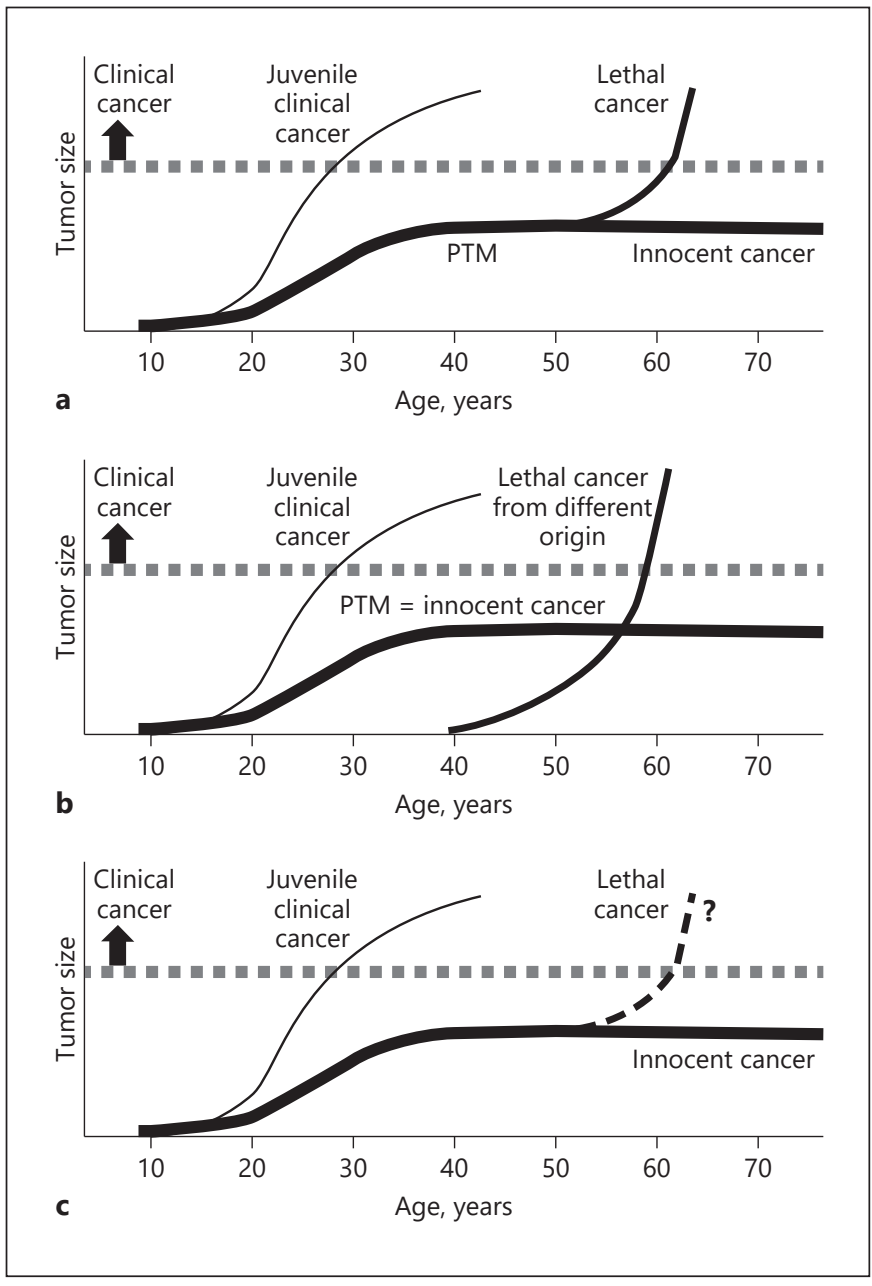

Fig. 1. Proposed models describing the fate of juvenile thyroid cancer. a The early-onset multistep carcinogenesis model. Thyroid cancers start proliferation before adolescence. A small number of them show rapid growth and become juvenile clinical cancer. The rest become PTMs. Some PTMs resume proliferation after several decades to turn into lethal cancer. $\mathbf{b}$ The fetal cell carcinogenesis model. Thyroid cancers start proliferation before adolescence. A small number of them show rapid growth and become juvenile clinical cancer. The rest become PTMs. These PTMs never turn into lethal cancer but become innocent cancer. Lethal cancers arise from a different origin. c The natural history of juvenile thyroid cancer estimated from the data from the FHMS and observation trials. Thyroid cancers start proliferation before adolescence. A small number of them show rapid growth and become juvenile clinical cancer. The rest become PTMs. No case has been reported of a PTM becoming lethal or undergoing anaplastic transformation. PTM, papillary thyroid microcarcinoma.

The first screening of the FHMS, which was performed prior to the latency period expected for the onset of radiation-induced thyroid cancer, was planned in order to collect baseline data. The prevalence of thyroid cancer 
showed a steep increase in the teens, suggesting that the first onset of carcinogenesis is likely to occur before adolescence and that tumors grow rapidly afterward (Fig. 2a) $[1,9]$. Another study showed a negative correlation between the size and growth rate of tumors found in children, which suggested that their growth is self-limiting [12].

Thyroid cancer in children shows enigmatic characteristics. It usually presents with a large neck nodule and is often accompanied by local or distant metastases [13, 14]. In fact, thyroid cancer detected in the FHMS showed aggressive features; for example, $>80 \%$ of them showed either local invasion or local or distant metastasis [15]. The recurrence rate of thyroid cancer in children after surgery is much higher than that in adults. However, the associated prognosis is extremely favorable and its cancer-specific mortality is $<2 \%$ in 10 years [16]. These characteristics can be understood easily when its self-limiting characteristics are taken into account. PTMs detectable with US exist at a high prevalence after middle age. Based on extensive data from health checkups in Japan, PTM is detected in about 1/200 individuals after the thirties [17]. Recent data from observation trials of PTMs proved an indolent feature of PTMs after middle age. Most of them stay at the same size, and some even shrink [18]. Data accumulated thus far support the concept that most papillary carcinomas are initiated in childhood, undergo a rapid growth period during adolescence and early adulthood, and become indolent or nonprogressive in middle age. These speculations are concordant with both Williams' and our model $[10,11]$.

The main difference between these 2 models is whether PTMs, once stopping growth, resume proliferation in the elderly. Although data from long-term observation trials of PTMs have been presented, there is no report of a PTM turning into a lethal cancer, or showing anaplastic transformation [19, 20]. Furthermore, recent experiences in Korea have shown that surgery to remove PTMs does not result in decreased cause-specific mortality [6]. There is little, if any, possibility that these PTMs become lethal after middle age (Fig. 1c).

\section{The Mechanism of Overdiagnosis of Juvenile Thyroid Cancer}

Overdiagnosis is the detection of a disease that does not do any harm to the patient throughout the lifetime [21]. Estimating based on data from autopsies, occult thyroid cancer that is found in children after the teens and
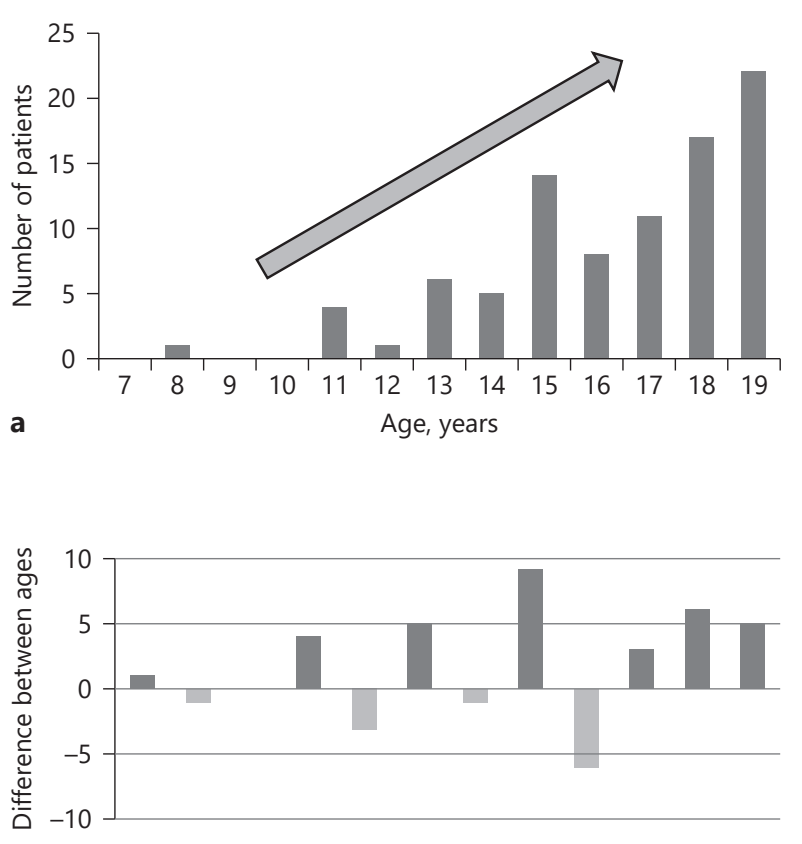

b

Fig. 2. Results of the first-round screening of school children in Fukushima. The number of patients diagnosed with thyroid cancer showed a steep increase in the teens $(\mathbf{a})$. b Shows the subtracted values between each successive age. The sum of these values represents the number of patients diagnosed with thyroid cancer each year.

its prevalence shows a steep increase until the early thirties [22]. On the other hand, the prevalence of clinical thyroid cancer in the teens is very low, and it increases very slowly until it shows a peak in the forties or fifties [23]. Thus, overdiagnosis of thyroid cancer is highly likely to happen in young generations from the late teens to early thirties. We should remember that, based on the above considerations, detection of small juvenile cancers by US results mostly in overdiagnosis but not diagnosis too early.

\section{Benefits and Harm of US-Based Thyroid Screening in the Young}

Since juvenile thyroid cancer is associated with an excellent prognosis, it is not likely that US screening decreases cancer-related mortality. Furthermore, it is not clear if early detection by US can improve the quality of 
life by preventing local or distant metastases or decreasing the recurrence rate. Thus, it is difficult to identify benefits of US-based thyroid screening in the young.

The main harm of US thyroid screening is overdiagnosis. The harm of overdiagnosis in the young is more serious than that in the elderly. Although there is little information at present, it can be easily speculated that stigmatization as a patient with thyroid cancer is the most serious threat for children. People regard children diagnosed with thyroid cancer as patients with "juvenile cancer." Although juvenile thyroid cancer is a rare exception, the general view of juvenile cancer is that it is serious and fatal. It is likely that children with thyroid cancer have to live their life as patients with a life-threatening disease. Fukushima residents had to face pubic and self-sigma toward the radiation effects $[24,25]$. The preconceived idea among the public that children in Fukushima were polluted by radiation makes their situations even worse. Such stigmatization may create unexpected obstacles in their school and job, and when they choose their spouse. In fact, the issue of most concern regarding children diagnosed with thyroid cancer in Fukushima and their parents is not health problems but the children's marriage [26].

The harm of overdiagnosis in the young tends to be underestimated when we solely focus on health problems. Overdiagnosis of thyroid cancer is closely related to the children's human rights. The children are likely to suffer from thyroid cancer more psychologically, socially, and economically than physiologically. Children diagnosed with thyroid cancer after the Chernobyl accident were at a high risk of attempting suicide [27,28]. It is difficult to conclude that Chernobyl suicides were related to thyroid cancer diagnosis; however, the possibility that it was a contributing stressor cannot be excluded.

In addition, in the young, it is difficult to perform active surveillance, which is now recommended for some PTMs in adults $[19,20]$. In the case of children, such an observation may last for more than half a century. Children with thyroid cancer must go through many life events that might change their lifestyle, such as entering a college or employment, marriage, or becoming pregnant. With each life event, they will worry and question whether they were right not to remove the thyroid cancer. Active surveillance forces the children to carry a heavy burden. In fact, in Fukushima, the majority of children with small thyroid cancer detectable only by US have already undergone surgery [15].

The US Preventive Services Task Force summarized the merits and demerits of US-based thyroid screening and concluded that US screening for asymptomatic individuals is not recommended since it causes more harm than good [29]. Considering the above discussion, such a conclusion is also true in children. Thyroid screening by US for asymptomatic children should be avoided. Recent guidelines from some countries and regions presented a concordant conclusion. They concluded they are not confident about the benefits of US screening even in the follow-up of children after a high-dose radiation exposure of the thyroid $[30,31]$. Recently, the International Agency for Research on Cancer recommended against population thyroid screening after a nuclear plant accident, because the harm outweighs the benefits at the population level [32]. Thus, the FHMS may be the last thyroid screening program, even if another nuclear plant accident occurs in the future.

\section{Overdiagnosis of Juvenile Thyroid Cancer in Fukushima: How Did It Happen?}

After the accident at Fukushima Daiichi Nuclear Plant, the experts did not expect an increasing prevalence of thyroid cancer. Learning lessons from the Chernobyl nuclear plant accident, the residents were protected from radiation exposure successfully [33]. However, the fear of thyroid cancer prevailed. The FHMS was started in order to reduce the residents' anxiety and collect data on their health. Based on the experience of the Chernobyl accident, it was believed that highly sensitive thyroid screening with US would contribute to the successful control of thyroid cancer. It is not likely that the experts who planned this program foresaw overdiagnosis, since in 2011, the fact that occult thyroid cancer exists at a high prevalence in the young was not generally recognized. In fact, until recently, there was no research paper except for some of ours describing the initiation of most thyroid cancers before adolescence [34]. Unexpectedly, over 100 thyroid cancers were found in the first-round screening, and such a result caused confusion among the residents [9].

Some experts explained to the residents that these cancers were detected by a pure screening effect, in other words, they would become clinical cancers after several decades, but their growth was so slow that they were detected as small cancers in children [35]. If this explanation had been correct, the number of patients would have markedly decreased in the second-round screening performed 2 years later. Such an idea resulted in neglecting the risk of overdiagnosis and might have contributed to the decision proceeding to the next screening. 
Analyzing the data in school children from the firstround screening carefully, it can easily be speculated that such an optimistic prediction was unlikely [9]. The prevalence of thyroid cancer shows a steep increase in the teens (Fig. 2a). The sum of the differences between ages in the first-round screening was 22 (Fig. 2b). Therefore, among school children, 44 cases will be predicted to be newly diagnosed with thyroid cancer every 2 years because thyroid cancer grows rapidly in the teens. In the second-round screening, 71 additional patients, including 53 school children, suspected to have thyroid cancer by fine needle aspiration cytology were identified, which resulted in even further confusion among the residents [36].

\section{Overdiagnosis of Juvenile Thyroid Cancer in Fukushima: How Did It Expand?}

The number of patients with juvenile thyroid cancer in Fukushima keeps increasing, simply because no change in the screening program has been made in the FHMS. It is clear that the more US-based thyroid screening is performed, the more overdiagnosis occurs. Then, why don't they try to stop US screening?

\section{Thyroid Screening in Fukushima Was Started as a \\ National Project}

Overdiagnosis of cancer is often associated with a large national project. For example in Korea, overdiagnosis of thyroid cancer was associated with a nationwide physical checkup [6]. The FHMS was designed by chief Japanese experts as a huge health management program with a budget of more than a billion dollars [8]. Thus, it can easily be imagined that there is a reluctance to admit harm among those responsible for the project. In fact, few opportunities for open discussion about the harm of the FHMS have yet been offered by related Japanese academic associations.

\section{Experts Underestimate the Harm of Overdiagnosis}

The concept of overdiagnosis is difficult to understand, not only for the public but also for some experts who believe that early detection and therapy is a golden rule for cancer treatment. Further, since thyroid cancer in children is an extremely rare disease, there are few physicians who have enough experience regarding patients with juvenile thyroid cancer and recognize the serious harm of overdiagnosis. In addition, a strong belief, although without any evidence, that the FHMS had helped to reduce the residents' anxiety, enhanced the motivation to continue the program. Furthermore, experts engaged in the thyroid screening program after the Chernobyl accident or introduction of thyroid US in health checkups are reluctant to admit the harm of US-based thyroid screening. Some experts explained US-based thyroid screening and subsequent surgery are carried out in more sophisticated manners to reduce the harm of overdiagnosis, and they expect early detection and less invasive surgery will increase the patients' quality of life, which might outweigh the harm $[37,38]$. Based on such a consideration, some members of the Task Force for Thyroid Examination and Prefectural Oversight Committee of the FHMS presented their opinion that the FHMS does not necessarily follow International Agency for Research on Cancer's recommendation that prohibits population thyroid screening [38].

\section{Misdirection by Antinuclear Plant Campaign and Media}

There is one situation clearly different from what happened in Korea. The increasing incidence of juvenile thyroid cancer in Fukushima can be used by some antinuclear plant campaigns to exaggerate the risk of radiation. People supporting such campaigns tend to emphasize the health problems caused by radiation in Fukushima but underestimate the risk of overdiagnosis. Such misleading opinions often appeared in some Japanese media. For example, Tsuda et al. [39] published a paper concluding that thyroid cancer in Fukushima was caused by radiation, but such a conclusion was refused by the United Nations Scientific Committee of the Effect of Atomic Radiation [40]. However, some media introduced it as one of the leading opinions among experts [41]. These circumstances make it difficult for residents of Fukushima to correctly understand their health problems.

\section{Thyroid Screening as a School Program}

For school children in Fukushima, thyroid screening was carried out as a school program in class time. It is psychologically difficult for parents to express their desire for their children not to undergo the examination, and it is likely that some children and their families mistakenly believe that participation is mandatory, like other health checkups done in schools [42].

\section{Insufficient Informed Consent}

The consent form provided prior to the examination does not contain a description about the harm of USbased thyroid screening. It only says, "A disease which 


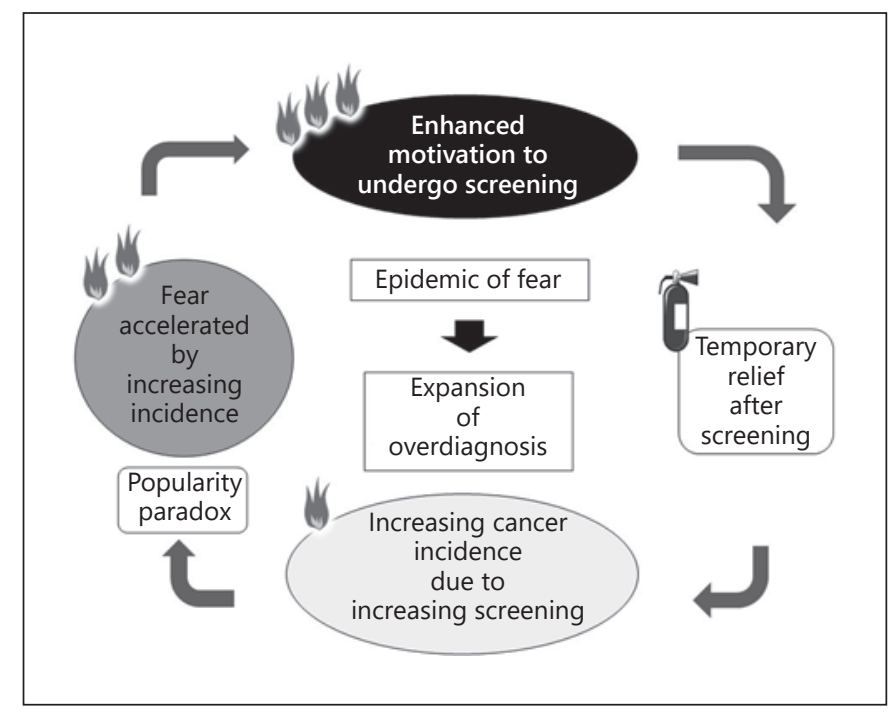

Fig. 3. Mechanism of epidemic of fear caused by thyroid screening. An increasing thyroid cancer incidence caused by screening together with the popularity paradox accelerates the fear of cancer, which leads to enhanced motivation to undergo thyroid screening. The residents may feel temporary relief if they are notified they do not have thyroid cancer. Such an experience strengthens their motivation to undergo subsequent screening, resulting in an increase of patients.

does not need any therapy might be detected, and it might worry you." [43] The results from the questionnaire answered by the participants of US-based thyroid screening showed that only $11.8 \%$ of them recognized the benefits or harm of US-based thyroid screening [44]. For these reasons, the participation rate is still over $80 \%$ in school children, which leads to further overdiagnosis [2].

\section{Epidemic of Fear}

The increasing incidence of juvenile thyroid cancer detected by the FHMS shocked the residents of Fukushi$\mathrm{ma}$, and fear of thyroid cancer became prevalent [45]. The trend in the frequency of searching for "thyroid cancer" though the Internet showed marked spikes when additional cases of thyroid cancer were reported. Furthermore, "thyroid cancer" has been searched for mainly inside Fukushima Prefecture [42]. These data show that even though thyroid screening was started in order to decrease residents' anxiety and fear, it actually triggered further anxiety. The increasing incidence of juvenile thyroid cancer and fear triggered by it can induce strong motivation to continue thyroid screening, regardless of the phenomenon of overdiagnosis (Fig. 3).

Overdiagnosis of Juvenile Thyroid Cancer

\section{Popularity Paradox}

Patients diagnosed with thyroid cancer in Fukushima and their parents are not likely to consider the harm of overdiagnosis, since they have to accept the incorrectness of the choice to have undergone thyroid screening when admitting overdiagnosis. They wish to believe that both thyroid screening and the resulting surgery were the right choices and are likely to recommend that others continue thyroid screening. This phenomenon is called the popularity paradox [46]. In fact, no claim concerning overdiagnosis has been put forward from patients or their parents diagnosed with thyroid cancer in the FHMS, and none of them wish to stop the screening [47].

\section{Ethical Concerns about the Thyroid Screening Program}

As occurred in Korea and the United States, overdiagnosis always accompanies some problems with medical ethics [48-51]. As described above, thyroid screening is likely to do more harm than good for children. The purpose of thyroid screening in Fukushima is to understand the effect of radiation on residents' health and reduce their anxiety [8]. However, neither directly benefits children who are the targets of thyroid screening. Medical research targeting humans is required to follow the Helsinki Declaration and it recommends to avoid researches which do more harm than good to the subjects [52]. Thus, from an ethical point of view, it is difficult to justify the present thyroid screening program in Fukushima.

Furthermore, the lack of informed consent and examination during class time in school, which is possibly regarded as an enforced examination, may also be a violation of the Helsinki declaration. These situations have occurred because it was generally believed that US-based thyroid screening did not harm children when the FHMS was started in 2011. However, recent data on the natural history of juvenile thyroid cancer have changed such an optimistic view. According to medical ethics, the local government should reconsider the present status and make appropriate modifications to the present protocol.

\section{Conclusion}

Early detection and treatment is not a golden rule for thyroid cancer anymore, and US-based thyroid screening is not harmless, but rather harmful to children without any symptoms. In a previous paper, to prevent the expan- 
sion of overdiagnosis, I proposed the following 3 reactions [53]: First, experts should publicize their honest opinions without any misleading caused by conflicts of interest. Second, residents should educate themselves to avoid the epidemic of fear and popularity paradox. Third, all related people should give priority to protecting children from the harm of overdiagnosis over their own interests. We should keep discussing overdiagnosis without hesitation, and every person engaged in the thyroid screening program in Fukushima should keep in mind that the first priority is to protect children' $s$ health and welfare, not protect his/her own practice.

\section{Disclosure Statement}

The author has no conflicts of interest to declare.

\section{Funding Sources}

No funding was acquired for this review.

\section{Author Contributions}

This review was written solely by T.T.

\section{References}

1 Office of International Cooperation. Radiation Medical Science Center for the Fukushima Health Management Survey [Internet]. Fukushima: The 28th Prefectural Oversight Committee Meeting for Fukushima Health Management Survey [cited 2019 Sep 10]. Available from: http://fmu-global.jp/survey/ the-28th-prefectural-oversight-committeemeeting-for-fukushima-health-management-survey/.

2 Office of International Cooperation. Radiation Medical Science Center for the Fukushima Health Management Survey [Internet]. Fukushima: The 33rd Prefectural Oversight Committee Meeting for Fukushima Health Management Survey [cited 2019 Sep 10]. Available from: http://fmu-global.jp/survey/ the-33rd-prefectural-oversight-committeemeeting-for-fukushima-health-management-survey/.

3 Marumori Town [Internet]. Miyagi: Result of the third thyroid screeening [cited 2019 Sep 10]. Available from: http://www.town.marumori.miyagi.jp/hokenhukushi/yokenyobou/ kojosen.html.

4 Kitaibaraki City [Internet]. Ibaraki: Result of thyroid US examination [cited 2019 Sep 10]. Available from: http://www.city.kitaibaraki. lg.jp/docs/2015082500032/files/koujousenn. pdf.

5 Katanoda K, Kamo K, Tsugane S. Quantification of the increase in thyroid cancer prevalence in Fukushima after the nuclear disaster in 2011-a potential overdiagnosis? Jpn J Clin Oncol. 2016 Mar;46(3):284-6.

6 Ahn HS, Kim HJ, Welch HG. Korea's thyroidcancer "epidemic"-screening and overdiagnosis. N Engl J Med. 2014 Nov;371(19):17657.

7 Kondo T, Ezzat S, Asa SL. Pathogenetic mechanisms in thyroid follicular-cell neoplasia. Nat Rev Cancer. 2006 Apr;6(4):292-306.
8 Office of International Cooperation. Radiation Medical Science Center for the Fukushima Health Management Survey [Internet]. Fukushima: Overview of the Fukushima Health Management Survey. [cited 2019 Sep 10]. Available from: http://fmu-global. jp/our-activities/health-management-survey/.

9 Suzuki S. Childhood and adolescent thyroid cancer in Fukushima after the Fukushima Daiichi Nuclear Power Plant accident: 5 years on. Clin Oncol (R Coll Radiol). 2016 Apr; 28(4):263-71.

10 Williams D. Thyroid Growth and Cancer. Eur Thyroid J. 2015 Sep;4(3):164-73.

11 Takano T. Fetal cell carcinogenesis of the thyroid: a modified theory based on recent evidence. Endocr J. 2014;61(4):311-20.

12 Midorikawa S, Ohtsuru A, Murakami M, Takahashi H, Suzuki S, Matsuzuka T, et al. Comparative analysis of the growth pattern of thyroid cancer in young patients screened by ultrasonography in Japan after a nuclear accident: The Fukushima Health Management Survey. JAMA Otolaryngol Head Neck Surg. 2018 Jan;144(1):57-63.

13 Chaukar DA, Rangarajan V, Nair N, Dcruz AK, Nadkarni MS, Pai PS, et al. Pediatric thyroid cancer. J Surg Oncol. 2005 Nov;92(2): 130-3.

14 Enomoto Y, Enomoto K, Uchino S, Shibuya $\mathrm{H}$, Watanabe S, Noguchi S. Clinical features, treatment, and long-term outcome of papillary thyroid cancer in children and adolescents without radiation exposure. World J Surg. 2012 Jun;36(6):1241-6.

15 Suzuki S, Bogdanova TI, Saenko VA, Hashimoto Y, Ito M, Iwadate M, et al. Histopathological analysis of papillary thyroid carcinoma detected during ultrasound screening examinations in Fukushima. Cancer Sci. 2019 Feb;110(2):817-27.

16 Vaisman F, Corbo R, Vaisman M. Thyroid carcinoma in children and adolescents-systematic review of the literature. J Thyroid Res. 2011;2011:845362.
17 Shimura H. Prevalence and clinical course of thyroid tumor in Japan: data from medical checkups. J Japan Thyroid Assoc. 2010 Apr; 1(1):109-13.

18 Miyauchi A, Kudo T, Ito Y, Oda H, Sasai H, Higashiyama T, et al. Estimation of the lifetime probability of disease progression of papillary microcarcinoma of the thyroid during active surveillance. Surgery. 2018 Jan; 163(1):48-52.

19 Ito Y, Miyauchi A, Kihara M, Higashiyama T, Kobayashi K, Miya A. Patient age is significantly related to the progression of papillary microcarcinoma of the thyroid under observation. Thyroid. 2014 Jan;24(1):27-34.

20 Sakai T, Sugitani I, Ebina A, Fukuoka O, Toda $\mathrm{K}$, Mitani $\mathrm{H}$, et al. Active surveillance for T1bN0M0 papillary thyroid carcinoma. Thyroid. 2019 Jan;29(1):59-63.

21 Welch HG, Black WC. Overdiagnosis in cancer. J Natl Cancer Inst. 2010 May;102(9):60513.

22 Takano T. Natural history of thyroid cancer [Review]. Endocr J. 2017 Mar;64(3):237-44.

23 Foundation for Promotion of Cancer Research [Internet]. Tokyo: Cancer statistics in Japan 2018 [cited 2019 Sep 10]. Available from: https://ganjoho.jp/en/professional/statistics/brochure/2018_en.html.

24 Maeda M, Oe M, Suzuki Y. Psychosocial effects of the Fukushima disaster and current tasks; Differences between natural and nuclear disasters. Hoken Iryou Kagaku. 2018 Feb; 67(1):50-8

25 Midorikawa S, Tanigawa K, Suzuki S, Ohtsuru A. Psychosocial issues related to thyroid examination after a radiation disaster. Asia Pac J Public Health. 2017 Mar;29(2_suppl suppl):63S-73S.

263.11 Fund for Children with Thyroid Cancer [Internet]. Tokyo: Present status of the children with thyroid cancer: questionnaire answered by 68 cases [cited 2019 Sep 10]. Available from: https://www.311kikin.org/wp311kikin/wp-content/uploads/2017/04/2017. 4.questionnaire.pdf. 
27 Contis G, Foley TP Jr. Depression, suicide ideation, and thyroid tumors among ukrainian adolescents exposed as children to chernobyl radiation. J Clin Med Res. 2015 May; 7(5):332-8.

28 Fridman MV, Man'kovskaia SV, Kras'ko OV, Demidchik IE. [Clinical and morphological features of papillary thyroid cancer in children and adolescents in the Republic of Belarus: analysis of 936 post-Chernobyl carcinomas]. Vopr Onkol. 2014;60(2):43-6.

29 Bibbins-Domingo K, Grossman DC, Curry SJ, Barry MJ, Davidson KW, Doubeni CA, et al.; US Preventive Services Task Force. Screening for thyroid cancer: US Preventive Services Task Force recommendation statement. JAMA. 2017 May;317(18):1882-7.

30 Francis GL, Waguespack SG, Bauer AJ, Angelos P, Benvenga S, Cerutti JM, et al.; American Thyroid Association Guidelines Task Force. Management guidelines for children with thyroid nodules and differentiated thyroid cancer. Thyroid. 2015 Jul;25(7):716-59.

31 Clement SC, Kremer LC, Verburg FA, Simmons JH, Goldfarb M, Peeters RP, et al. Balancing the benefits and harms of thyroid cancer surveillance in survivors of Childhood, adolescent and young adult cancer: Recommendations from the international Late Effects of Childhood Cancer Guideline Harmonization Group in collaboration with the PanCareSurFup Consortium. Cancer Treat Rev. 2018 Feb;63:28-39.

32 Togawa K, Ahn HS, Auvinen A, Bauer AJ, Brito JP, Davies L, et al. Long-term strategies for thyroid health monitoring after nuclear accidents: recommendations from an Expert Group convened by IARC. Lancet Oncol. 2018 Oct;19(10):1280-3.

33 Office of International Cooperation. Radiation Medical Science Center for the Fukushima Health Management Survey [Internet]. Fukushima: Preliminary report: Basic survey [cited 2019 Sep 10]. Available from: http:// fmu-global.jp/survey/preliminary-report-basic-survey/.
34 Takano T, Amino N. Fetal cell carcinogenesis: a new hypothesis for better understanding of thyroid carcinoma. Thyroid. 2005 May;15(5): 432-8.

35 Fukushima Prefecture [Internet]. Fukushima: Interim summary of the FHMS. [cited 2019 Sep 10]. Available from: https://www.pref.fukushima.lg.jp/uploaded/attachment/158522. pdf.

36 Ohtsuru A, Midorikawa S, Ohira T, Suzuki S, Takahashi H, Murakami M, et al. Incidence of thyroid cancer among children and young adults in Fukushima, Japan, screened with 2 rounds of ultrasonography within 5 years of the 2011 Fukushima Daiichi Nuclear Power Station accident. JAMA Otolaryngol Head Neck Surg. 2019 Jan;145(1):4-11.

37 Suzuki S. Management of thyroid cancer detected in heath checkup: Indication for operation. Official J Japan Assoc Endoc Surg Japan Soc Thyroid Surg. 2018 Aug;35(2):70-6.

38 Fukushima Prefecture [Internet]. Fukushima: The 12th meeting of Task Force for Thyroid Examination [cited 2019 Sep 10]. Available from: http://www.pref.fukushima.lg.jp/uploaded/attachment/322251.pdf.

39 Tsuda T, Tokinobu A, Yamamoto E, Suzuki E. Thyroid cancer detection by ultrasound among residents ages 18 years and younger in Fukushima, Japan: 2011 to 2014. Epidemiology. 2016 May;27(3):316-22.

40 Ishikawa T. Radiation doses and associated risk From the Fukushima Nuclear Accident. Asia Pac J Public Health. 2017 Mar;29(2_sup$\mathrm{pl}$ suppl):18S-28S.

41 The Mainichi [Internet]. Tokyo: Expert divided on causes of high thyroid cancer rates among Fukushima children [cited 2019 Sep 10]. Available from: https://mainichi.jp/ english/articles $/ 20160307 / \mathrm{p} 2 \mathrm{a} / 00 \mathrm{~m} / 0 \mathrm{na} /$ 022000c.

42 Synodos [Internet]. Japan: "Children in Fukushima are all right"-Message from Thyroid Examination Site. Ryugo Hayano \& Sanae Midorikawa (Reporter: Misaki Hattori) [cited 2019 Sep 10]. Available from: https://synodos. jp/science/21422.
43 Governor of Fukushima Prefecture [Internet]. Fukushima: Information about thyroid examination [cited 2019 Sep 10]. Available from: http://fukushima-mimamori.jp/thyroid-examination/media/pdf_osirase_douisho_download.pdf.

44 Synodos [Internet]. Japan: How much are risk and benefit perceived on thyroid cancer screening test? [cited 2019 Sep 10]. Available from: https://synodos.jp/fukushima_report $/ 22564$.

45 Normile D. Epidemic of fear. Science. 2016 Mar;351(6277):1022-3.

46 Raffle AE, Gray JA. Popularity paradox. Screening: evidence and practice. Oxford: Oxford University Press; 2007. p. 68.

47 3.11 Fund for Children with Thyroid Cancer [Internet]. Tokyo: Questionnaire about thyroid screening [cited 2019 Sep 10]. Available from: https://311kikin.org/wp-311kikin/wpcontent/uploads/2017/12/2017questionnai re-thyroid-ultrasound.pdf.

48 Brito JP, Hay ID. Thyroid cancer: overdiagnosis of papillary carcinoma - who benefits? Nat Rev Endocrinol. 2017 Mar;13(3):131-2.

49 Rogers WA, Craig WL, Entwistle VA. Ethical issues raised by thyroid cancer overdiagnosis: A matter for public health? Bioethics. 2017 Oct;31(8):590-8.

50 Takano T. Overdiagnosis of thyroid cancer: the children in Fukushima are in danger. Arch Pathol Lab Med. 2019 Jun;143(6):660-1.

51 Schnadig VJ. Overdiagnosis of thyroid cancer: is this not an ethical issue for pathologists as well as radiologists and clinicians? Arch Pathol Lab Med. 2018 Sep;142(9):1018-20.

52 General Assembly of the World Medical Association. World Medical Association Declaration of Helsinki: ethical principles for medical research involving human subjects. J Am Coll Dent. 2014;81(3):14-8.

53 Takano T. Overdiagnosis of thyroid cancer in Fukushima. Jap J Risk Analysis. 2019 Apr; 28(2):67-76. 